Saudi Journal of Medical and Pharmaceutical Sciences

Abbreviated Key Title: Saudi J Med Pharm Sci

ISSN 2413-4929 (Print) |ISSN 2413-4910 (Online)

Scholars Middle East Publishers, Dubai, United Arab Emirates

Journal homepage: http://scholarsmepub.com/sjmps/

Original Research Article

\title{
Formulation and Optimization of Oil Entrapped Floating Alginate Beads of Diclofenac Sodium
}

\author{
Uday Prakash , Dr. Atul Kumar Gangwar, Dr. Lalit Singh \\ S.R.Institute of Pharmacy, Bhuta, Bareilly, U.P. 243001 India
}

DOI: $10.36348 /$ sjmps.2020.v06i01.006

| Received: 08.12.2019 | Accepted: 22.12.2019 | Published: 14.01.2020

*Corresponding author: Uday Prakash

\section{Abstract}

The objective of present investigation is to prepare and optimize an oral floating alginate gel beads of Diclofenac sodium using sodium alginate and oils was utilized as a dispersed phase to generate a uniform emulsion to create multiple tiny chambers in the alginate matrix for better buoyancy. Diclofenac sodium loaded beads were prepared by emulsion gelatin method. In this method pre gelation liquid of sodium alginate solution $(2-4 \% \mathrm{w} / \mathrm{v})$ was prepared. Oil (Light liquid paraffin, coconut oil, and olive oil) in the concentration $(10 \%, 20 \%$ and $30 \%$, was then added to the polymer solution. From the results formulation F3 was chosen as the most optimized formulation as it possessed all the required physicochemical characters and sustained drug release. The in vitro release data fitted with higher values in matrix model and the release was found to be Non- Fickian diffusion (anomalous transport) as the $\mathrm{n}$ value is in between 0.5 to 1 . Entrapment efficiency and drug release of optimized batch FL3 were found to be $78.22 \%$ and $92.63 \%$ respectively. Drug absorption from the gastrointestinal tract is highly variable process and prolonging gastric retention of the dosage form is a challenging task. Under such circumstances, floating drug delivery system proves to be promising approach for gastric retention. The optimization of floating, drug entrapment efficiency and drug release behavior of Diclofenac beads was done by applying design expert

Keywords: Diclofenac sodium, FL3, Emulsion gelatine method, Sodium alginate.

Copyright @ 2020: This is an open-access article distributed under the terms of the Creative Commons Attribution license which permits unrestricted use, distribution, and reproduction in any medium for non-commercial use (NonCommercial, or CC-BY-NC) provided the original author and source are credited.

\section{INTRODUCTION}

The objective of controlled release drug delivery includes two important aspects, namely spatial placement and temporal delivery of the drug. Spatial placement relates to targeting a drug to a specific organ or tissue. While temporal delivery refers to controlling the rate of drug delivery to the target tissue [1].

An appropriately designed controlled release drug delivery system can be major advance towards solving these two problems. It is for this reason that the science and technology responsible for development of controlled release pharmaceuticals have been and continue to be the focus of a great deal of attention in both industrial and academic laboratories [2].

In the exploration of oral controlled release drug administration one encounters three areas of potential challenges.

- Development of a drug delivery system-capable of delivering a drug at a therapeutically effective rate to a desirable site for duration required for potential treatment.

- Modulation of G.I. transit time so that the drug delivery system developed can be transported to a target site or to the vicinity of absorption site and reside there for a prolonged period of time to maximize the delivery of a drug dose.

- Minimization of hepatic first pass elimination, If the drug to be delivered is subjected to extensive hepatic first pass elimination, preventive measures should be devised to either by pass or minimize the extent of hepatic metabolic effect[3].

\section{EXPERIMENTAL METHOD Material}

Diclofenac sodium procured from New Era Scientific, Meerut. But Calcium Chloride \& Sodium Hydroxide procured from Thermo Fisher Scientific India Pvt. Ltd. Most important drug, Sodium Alginate procured from Loba Cheime Pvt Ltd. All chemicals used for work, were analytical grade. 
Uday Prakash et al; Saudi J Med Pharm Sci, Jan., 2020; 6(1): 37-41

\section{Method of Preparation of micro beads}

Diclofenac sodium loaded beads were prepared by "Emulsion Gelatin Method". In this method pre-gelation liquid of sodium alginate solution $(2-4 \%$ w/v) was prepared. Oil (Light liquid paraffin, coconut oil, and olive oil) in the concentration $10 \%$, $20 \%$ and $30 \%$ was then added to the polymer solution. To ensure emulsion stabilization, the mixtures were homogenized at $1000 \mathrm{rpm}$ using a homogenizer (Remimotors (Mumbai, India) for $20 \mathrm{~min}$ with the addition of emulsifier Span 80(Sorbitan monooleate). Diclofenac sodium was then dispersed in the formed emulsion. The bubble free emulsion was extruded, using a 20 gauge syringe needle into $100 \mathrm{ml}$ of gently agitated $(4 \%, \mathrm{w} / \mathrm{w})$ $\mathrm{CaCl}_{2}$ solution at room temperature. The emulsion gel beads were allowed to stand in the solution for $40 \mathrm{~min}$ before being separated and washed with distilled $\mathrm{H}_{2} \mathrm{O}$. The beads were dried in the tray dryer oven [4]. Factorial design was used in this study and 2 factors were evaluated, each at 3 levels, experimental trials were performed at all 27 possible combinations. The amount of sodium alginate and oils (X2) were selected as independent variables. All other formulation and processing variables were kept invariant throughout the study. The resulting data were fitted into Design Expert Software (V.8.0.7.1) and analysed statistically using analysis of variance (ANOVA). The data were also subjected to 3-D response surface methodology to determine the influence of sodium alginate and oils on dependent variables [5].

\section{Experimental design [6]}

Table-1: Experimental design for preparation of oil entrapped beads

\begin{tabular}{|c|c|c|c|c|c|}
\hline \multirow{2}{*}{$\begin{array}{c}\text { S. } \\
\text { No. }\end{array}$} & \multirow{2}{*}{ Batch code } & \multicolumn{2}{|c|}{ Actual level of factor } & \multicolumn{2}{c|}{ Level of factor } \\
\cline { 3 - 6 } & & $\begin{array}{c}\text { Sodium Alginate } \\
(\boldsymbol{\%}, \mathbf{X 1})\end{array}$ & Oil (\%, X2) & Sodium Alginate (\%, X1) & Oil (\%, X2) \\
\hline 1 & F1 & 2 & 10 & -1 & -1 \\
\hline 2 & F2 & 2 & 20 & -1 & 0 \\
\hline 3 & F3 & 2 & 30 & -1 & +1 \\
\hline 4 & F4 & 3 & 10 & 0 & -1 \\
\hline 5 & F5 & 3 & 20 & 0 & +1 \\
\hline 6 & F6 & 3 & 10 & 0 & -1 \\
\hline 7 & F7 & 4 & 20 & +1 & 0 \\
\hline 8 & F8 & 4 & 30 & +1 & +1 \\
\hline 9 & F9 & 4 & +1 & \\
\hline
\end{tabular}

\section{Determination of buoyancy of beads}

Floating properties of beads were evaluated using USP dissolution apparatus containing $500 \mathrm{ml}$ SGF $\mathrm{pH}$ (7.4). The temperature of medium was maintained at $37 \pm 5^{\circ} \mathrm{C}$ fifty beads were placed in the media and total floating time was measured by visual observation.

\section{Swelling properties}

The swelling properties of prepared micro beads were determined in acidic buffer pH1.2. Thirty dried bead were placed in a beaker to which $200 \mathrm{ml}$ of buffer solution and then stirred with a magnetic stirrer at a speed $50 \mathrm{rpm}$. After $1 \mathrm{hr}$ interval, the equilibrium swollen beads were observed and measured under optical microscope. The magnitude of swelling was presented by the ratio of the mean diameter of swollen beads to the mean diameter of the dried beads before the test [7].

\section{In-Vitro Dissolution Studies}

The physic-chemical property of most drugs that has greatest influence on their absorption characteristics from the GIT is dissolution rate. "The drug is expected to release from the solid dosage forms (granules, tablets, capsules etc) and immediately go into molecular solution. This process is called as dissolution" $[8,9]$.

\section{Statistical analysis of the data and validation of the model}

The targeted response parameters were statistically analyzed by applying one way ANOVA (analysis of variance) and significance of the model was estimated using the statistical package Design Expert ( 8.0.7.1 trial version). The individual parameters were evaluated using "f test" and mathematical relationship was generated between the factors (independent variables) and the responses (dependent variables) using multiple linear regression analysis for determining the level of factors which yield optimum dissolution responses.

\section{RESULTS}

Central composite design (face-centered) was used in this study and 2 factors were evaluated, each at 3 levels, experimental trials were performed at all 27 possible combinations. The amount of sodium alginate and oils (X2) were selected as independent variables. All other formulation and processing variables were kept invariant throughout the study. The resulting data were fitted into Design Expert Software (V 8) and analyzed statistically using analysis of variance (ANOVA). The data were also subjected to 3-D response surface methodology to determine the influence of sodium alginate and oils on dependent variables. 
Table-2: Determination of particle sizes of beads

\begin{tabular}{|c|c|c|c|c|}
\hline $\begin{array}{c}\text { S. } \\
\text { No. }\end{array}$ & Formulation & Olive oil & Coconut oil & Light liquid paraffin oil \\
\hline 1 & F1 & $1.70 \pm 0.14$ & $1.72 \pm 0.12$ & $1.17 \pm 0.17$ \\
\hline 2 & F2 & $1.82 \pm 0.14$ & $1.85 \pm 0.13$ & $1.22 \pm 0.14$ \\
\hline 3 & F3 & $1.92 \pm 0.15$ & $1.98 \pm 0.16$ & $1.38 \pm 0.20$ \\
\hline 4 & F4 & $2.10 \pm 0.10$ & $2.21 \pm 0.18$ & $2.10 \pm 0.14$ \\
\hline 5 & F5 & $2.25 \pm 0.10$ & $2.35 \pm 0.20$ & $2.19 \pm 0.17$ \\
\hline 6 & F6 & $2.47 \pm 0.16$ & $2.65 \pm 0.16$ & $2.32 \pm 0.13$ \\
\hline 7 & F7 & $2.85 \pm 0.14$ & $2.72 \pm 0.13$ & $2.43 \pm 0.11$ \\
\hline 8 & F8 & $2.90 \pm 0.16$ & $2.83 \pm 0.12$ & $2.58 \pm 0.13$ \\
\hline 9 & F9 & $2.97 \pm 0.18$ & $2.98 \pm 0.18$ & $2.63 \pm 0.15$ \\
\hline
\end{tabular}

Table-3: Determination of buoyancy of beads

\begin{tabular}{|c|c|c|c|c|c|c|}
\hline S. No. & Formulation & $\begin{array}{c}\text { Conc. of oil } \\
(\boldsymbol{\%})\end{array}$ & $\begin{array}{c}\text { Buoyancy(h) } \\
\text { Coconut oil }\end{array}$ & $\begin{array}{c}\text { Buoyancy(h) } \\
\text { Olive oil }\end{array}$ & $\begin{array}{c}\text { Buoyancy(h) } \\
\text { Light liquid } \\
\text { paraffin }\end{array}$ & Shape \\
\hline 1 & F1 & 10 & 7 & 8 & 9 & Spherical \\
\hline 2 & F2 & 20 & 9 & 9 & 11 & Spherical \\
\hline 3 & F3 & 30 & 10 & 10 & 7 & Spherical \\
\hline 4 & F4 & 10 & 7 & 7 & 8 & Spherical \\
\hline 5 & F5 & 20 & 8 & 9 & 12 & Spherical \\
\hline 6 & F6 & 30 & 9 & 10 & 9 & Spherical \\
\hline 7 & F7 & 10 & 9 & 8 & 10 & Spherical \\
\hline 8 & F8 & 20 & 7 & 9 & 12 & Spherical \\
\hline 9 & F9 & 30 & 9 & 10 & 9 & Spherical \\
\hline
\end{tabular}

Table-4: Table of drug entrapment efficiency of coconut, Light liquid paraffin and olive oil

\begin{tabular}{|c|c|c|c|c|}
\hline S. No. & Formulation & Olive oil & Coconut oil & $\begin{array}{c}\text { Light liquid } \\
\text { paraffin }\end{array}$ \\
\hline 1 & F1 & $40.14 \%$ & $52.12 \%$ & $65.32 \%$ \\
\hline 2 & F2 & $56.21 \%$ & $55.32 \%$ & $71.12 \%$ \\
\hline 3 & F3 & $58.13 \%$ & $58.12 \%$ & $78.22 \%$ \\
\hline 4 & F4 & $43.15 \%$ & $50.15 \%$ & $68.32 \%$ \\
\hline 5 & F5 & $46.12 \%$ & $54.18 \%$ & $75.43 \%$ \\
\hline 6 & F6 & $57.32 \%$ & $57.13 \%$ & $80.21 \%$ \\
\hline 7 & F7 & $44.15 \%$ & $53.21 \%$ & $74.13 \%$ \\
\hline 8 & F8 & $50.23 \%$ & $55.24 \%$ & $84.18 \%$ \\
\hline 9 & F9 & & \\
\hline
\end{tabular}

Table 5: drug release of light liquid paraffin

\begin{tabular}{|c|c|}
\hline Batch code & Drug release $(\mathbf{\%})$ \\
\hline FL1 & 97.99 \\
\hline FL2 & 94.54 \\
\hline FL3 & 92.63 \\
\hline FL4 & 88.92 \\
\hline FL5 & 80.44 \\
\hline FL6 & 78.88 \\
\hline FL7 & 76.83 \\
\hline FL8 & 73.99 \\
\hline FL9 & 70.04 \\
\hline
\end{tabular}

\section{DISCUSSION}

An attempt was formulate made to oil entrapped floating beads of Diclofenac sodium. The drug and polymers were subject for compatibility studies by FTIR. The beads were prepared by inotropic gelation technique. The prepared beads were evaluated for various physicochemical parameters such as, morphology, swelling studies, floating charactertics, drug entrapment efficiency and in-vitro release studies.

Traditionally, pharmaceutical formulators develop formulations by changing one variable at a time and method is time consuming. It is therefore important to understand the influence of formulation variables on the formulation quality with a minimal number of trials and subsequent selection of formulation variables to develop optimized formulation using established statistical tools such as factorial design. For the $3^{2}$ factorial design, a total 27 trial formulations were prepared by Design-Expert 8.0.6.1 software for three two independent variables: sodium alginate and oils, which were varied at three different levels (low, medium and high). The effect of these 
independent variables on Drug entrapment efficiency $(\%)$, buoyancy $(\mathrm{h})$, Particle size $(\mathrm{mm})$ and drug release (\%) were investigated as optimization response parameters in the study. According to this trial proposal, various oil entrapped alginate beads containing Diclofenac sodium were prepared by iontropically emulsion gelation technique. Graphical optimization was performed by superimposing the countour plots (Figs.1 \& 2) of all four responses and locating the area of interest (optimal surface) common to all four plots. Since optimal area was small, only one formulation was chosen in centre of the area.

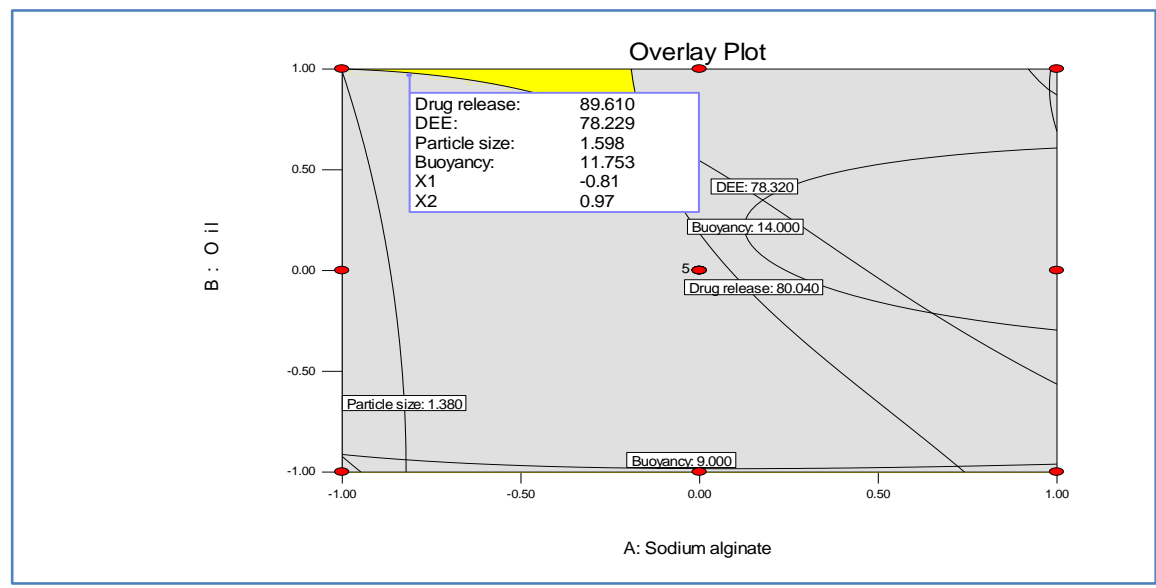

Fig-1: Optimized formulation in area of interest in overlay plot

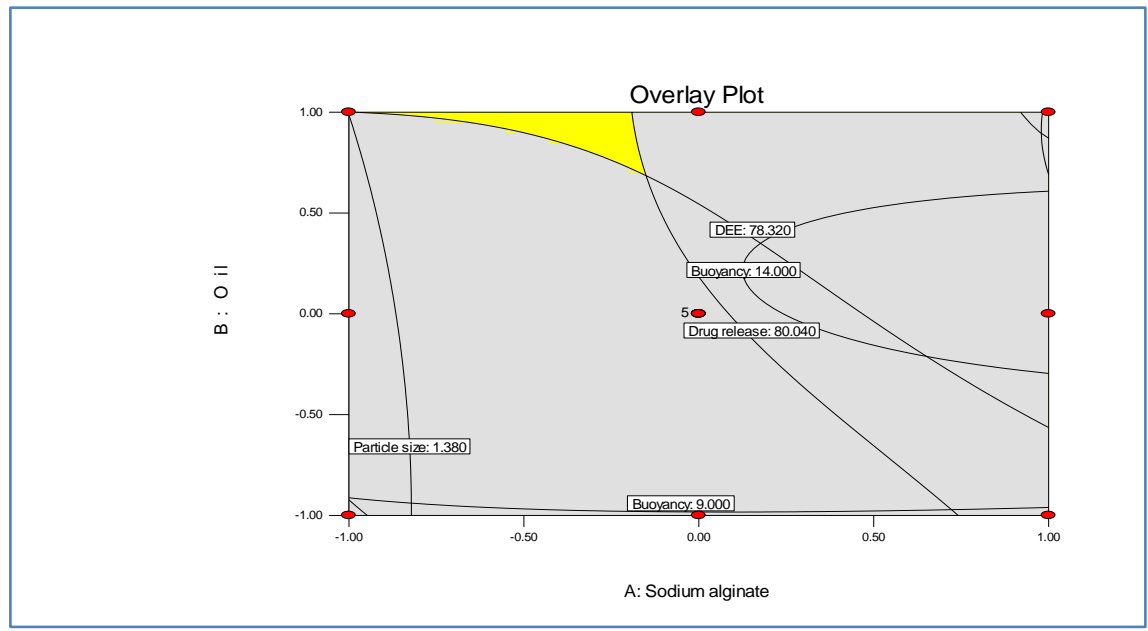

Fig-2: Overlay plot showing area of interest in yellow region

To verify the reproducibility the optimized formulations were prepared according to the predicted independent variables and evaluated for the responses. The results showed a good closeness between experimental and predicted values, which confirms the practicability of the models developed. The results are shown in (Table 6).
It can be observed from (Table 6 ) that $\mathrm{R}^{2}$ is high for all responses, which indicates a high degree of correlation between the experimental and predicted responses. In addition, the predicted $\mathrm{R}^{2}$ value is in good agreement with the adjusted $\mathrm{R}^{2}$ value, resulting in reliable models.

Table-6: Model Summary Statistics-Influence of formulation variables on the response factors

\begin{tabular}{|c|c|c|c|c|}
\hline Response Factor & St. Dev & $\mathbf{R}^{\mathbf{2}}$ & Adjusted R $^{\mathbf{2}}$ & Predicted R $^{\mathbf{2}}$ \\
\hline Drug release & 1.39 & 0.9835 & 0.9717 & 0.8636 \\
\hline Drug entrapment & 0.20 & 0.9994 & 0.9987 & 0.9352 \\
\hline Particle size & $6.499 \mathrm{E}-003$ & 0.9999 & 0.9998 & 0.9914 \\
\hline Buoyancy & 0.93 & 0.8782 & 0.8276 & -7.3478 \\
\hline
\end{tabular}


Table-7: Check point variables

\begin{tabular}{|c|c|c|}
\hline Batch code & X1 (sodium alginate) & X2 Oil \\
\hline FL1 & -0.81 & 0.97 \\
\hline FL2 & -0.58 & 0.98 \\
\hline FL3 & -0.20 & 0.97 \\
\hline FL4 & -0.17 & 0.71 \\
\hline
\end{tabular}

Table-8: Result of optimize batch

\begin{tabular}{|c|c|c|c|c|}
\hline Check point variables & Drug entrapment & Drug release & Particle size & Buoyancy \\
\hline FL1 & 78.229 & 89.610 & 1.598 & 11.753 \\
\hline FL2 & 78.590 & 85.758 & 1.839 & 11.835 \\
\hline FL3 & 79.346 & 80.194 & 2.171 & 11.994 \\
\hline FL4 & 78.214 & 80.214 & 2.157 & 12.917 \\
\hline
\end{tabular}

From the results formulation F3 was chosen as the most optimized formulation as it possessed all the required physicochemical characters and sustained drug release. The in vitro release data fitted with higher values in matrix model and the release was found to be Non- Fickian diffusion (anomalous transport) as the $\mathrm{n}$ value is in between 0.5 to 1 .

\section{CONCLUSION}

Entrapment efficiency and drug release of optimized batch FL3 were found to be $78.22 \%$ and $92.63 \%$ respectively. Mean particle size were found to be $1.38 \mathrm{~mm}$. Buoyancy was found to be $12 \mathrm{~h}$. The optimization of floating, drug entrapment efficiency and drug release behavior of Diclofenac beads was done by applying Design Expert. From kinetic modeling of the dissolution profile of the optimized formulation, it can be concluded that there is controlled release diffusion of Diclofenac sodium from the alginate beads.Stability studies of the optimized formulation were carry out stability testing at $25^{\circ} \mathrm{C}, 30^{\circ} \mathrm{C}$ and $40^{\circ} \mathrm{C}$ temperatures for a period of 3 months and show that there was no major effect of temperature on $\%$ drug release.

\section{REFERENCES}

1. Singh, B., \& Kwon, H. (2002). Drug delivery oral route, Encyclopedia Pharmaceutical Technology. 1242-1262

2. Charles, S.L., \& Joesph, R. (1999). Sustained release drug delivery systems. Remington's

Pharmaceutical Sciences, $19^{\text {th }}$ ed., Mac Publishing Company.1660-1663.

3. Chein, W. Yie. (1992). Oral drug delivery and delivery systems, $2^{\text {nd }}$ ed. Marcel Dekker Inc. New York, 139-141.

4. Bakan, J. A. (1987). Microencapsulation. The Theory and Practice of Industrial Pharmacy, $3^{\text {rd }}$ ed. Varghese Publishing House, Bombay, 42.

5. Subrahmanyam, C.V.S. (2000). Text Book of Physical Pharmaceutics", $2^{\text {nd }}$ ed Vallabh Prakashan, 85.

6. The United States Pharmacopoeia XXIV- NFXIX. (2000). Asian Edition USP Convention Inc, 17391742.

7. Cheng, G., AN, F., Zou, M. J., Sun, J., Hao, X. H., \& He, Y. X. (2004). Time-and pH-dependent colon-specific drug delivery for orally administered diclofenac sodium and 5aminosalicylic acid. World Journal of Gastroenterology: WJG, 10(12), 1769.

8. Manna, A., Ghosh, I., Goswami, N., Ghosh, L. K., \& Gupta, B. K. (1999). Design and evaluation of an oral controlled release microparticulate drug delivery system of nimesulide by ionotropic gelation technique and statistical optimization by factorial analysis.

9. Mirghani, A., Idkaidek, N. M., Salem, M. T. S., \& Najib, N. M. (2000). Formulation and release behavior of diclofenac sodium in Compritol 888 matrix beads encapsulated in alginate. Drug development and industrial pharmacy, 26(7), 791795.

10. Tønnesen, H. H., \& Karlsen, J. (2002). Alginate in drug delivery systems. Drug development and industrial pharmacy, 28(6), 621-630. 